\title{
IDENTIDADE ÉTNICA \\ OU IDENTIDADES \\ ÉTNICAS? A \\ ITALIANIDADE EM \\ OSWALDO TRUZZI
}

\section{- Renata Geraissati Castro de Almeida ${ }^{1}$}

Universidade Estadual de Campinas

Campinas - São Paulo - Brasil

Resenha do livro: TRUZZI, Oswaldo Mario Serra. Italianidade no interior paulista - percursos e descaminhos de uma identidade étnica (1880-1950). São Paulo: Editora Unesp, 2016.

Entre os anos de 1881 e 1915, cerca de 31 milhões de imigrantes chegaram à América no período classificado como o das grandes migrações. ${ }^{2}$ Estes deslocamentos ensejaram contatos entre pessoas de diferentes formações culturais que tornaram a construção de uma identificação de si um fenômeno recorrente ao longo dos séculos XIX e XX.

\footnotetext{
${ }^{1}$ Doutoranda no Departamento de História do Instituto de Filosofia e Ciências Humanas da Universidade Estadual de Campinas - Unicamp. E-mail: rgeraissati@gmail.com.

2 KLEIN, Herbert. Migrações internacionais na história da América. In: FAUSTO, Boris. Fazer a América. São Paulo: Editora da Universidade de São Paulo, 2000, p. 23.
} 
Inserido na produção que analisa essa conjuntura está o livro publicado em 2016, Italianidade no interior paulista: percursos e descaminhos de uma identidade étnica (1880-1950), pelo professor da Universidade Federal de São Carlos, Oswaldo Truzzi. Seu objetivo é compreender como se deu o processo de estruturação de uma identidade étnica do grupo de indivíduos que emigraram da Itália no recorte temporal que abrange os anos de 1880 a 1950. O espaço geográfico privilegiado em sua análise é o interior paulista, pertencente ao estado que possuiu o maior afluxo migratório brasileiro neste contexto; do total de imigrantes que vieram ao Brasil, 57,7\% optaram por São Paulo. ${ }^{3}$

O pesquisador é formado em Engenharia de Produção pela Universidade de São Paulo (1979), mestre em administração de empresas com a dissertação Café e indústria (1850-1950) - o caso de São Carlos pela Fundação Getúlio Vargas, SP (1985) e doutor em Ciências Sociais com o estudo Patrícios - sírios e libaneses em São Paulo pela Universidade Estadual de Campinas (1993). Sua tese de doutorado elucidou o processo da integração entre migração e imigração e salientou que há contextos específicos tanto na pátria de origem quanto na que os recepciona que possibilitam a estes indivíduos permanecerem em locais por vezes com costumes diversos.

Também autor do livro Sírios e libaneses: narrativa de história e cultura (2005), Truzzi propõe, por meio de uma análise quantitativa, uma periodização para as levas migratórias deste grupo. É coautor de livros que sistematizam informações sobre a imigração como Atlas da imigração internacional em São Paulo (1850-1950), Roteiro de fontes sobre a imigração em São Paulo (1850-1950) e Repertório da legislação brasileira e paulista referente à imigração, todos publicados em 2008 pela Editora Unesp. Entre os anos de 1990 e 2002, foi pesquisador do grupo de História Social da Imigração do Instituto de Estudos Econômicos, Sociais e Políticos de São Paulo (Idesp) que visava a preencher a lacuna sobre a imigração de caráter urbano. Sua trajetória acadêmica e sua inserção em grupos como a Red de Estudios Migratorios Transatlánticos indicam sua importância no tema.

O livro, dividido em cinco capítulos, principia por apresentar quais foram as concepções teórico-metodológicas utilizadas para estruturar sua noção de identidade. No primeiro capítulo, "à guisa de uma introdução teórica", o autor propõe que a identidade étnica é essencialmente uma fronteira social, produto da relação entre o imigrante, seu próprio grupo e sua socieda-

OLIVEIRA, Lúcia Lippi. O Brasil dos imigrantes. Rio de Janeiro: Jorge Zahar Ed., 2002, p. 22. 
de receptora. Ao perscrutar as diversas camadas sobrepostas na identidade italiana, visa mostrá-la como um processo histórico constantemente negociado, em que ora ocorre a aceitação, ora a resistência à assimilação. Dessa forma, ao migrarem, inevitavelmente as culturas tradicionais passam por alterações (p. 17). Truzzi entende que a experiência social destes imigrantes se localiza em uma zona de intersecção entre background social, econômico e cultural de sua terra de origem, contexto político e econômico de ambas as nações no período de migração e condicionantes de inserção na nova terra com suas oportunidades de mobilidade (p. 20).

Para a construção da "italianidade", uma forma de identificação a partir de uma experiência social heterogênea, o pesquisador se referencia na noção de comunidade imaginada proposta por Benedict Anderson que consiste em um sentimento de pertencimento a uma identidade nacional forjada. Entretanto, ao longo das páginas seguintes, demonstra que as primeiras levas migratórias advindas de uma Itália recém unificada possuíam vinculações com suas regiões de origem, identificando-se como calabreses, vênetos, dentre outros, e não com o Estado-nação italiano, algo que leva o leitor a indagar-se ao longo do livro se será possível emergir de fato a "italianidade".

No capítulo "A profusão de italianos no interior paulista", é reafirmada a importância do tema ao compilar bibliografia que analisa a imigração advinda da Itália: as cifras atestam que 57\% dos imigrantes aportados no Brasil entre 1886 e 1900 provinham dessas regiões. Para possíveis questionamentos quanto ao recorte centrar-se no interior paulista, o autor retoma Thomas Holloway que estima que, nos anos 1893-1910, nove entre dez imigrantes que deixaram a hospedaria do Brás se dirigiram ao oeste paulista, sobretudo próximos à Ferrovia Paulista (São Carlos) e à Ferrovia Mogiana (Ribeirão Preto) (p. 23).

Para compreender o percurso que foi desenvolvido pela "italianidade" no interior paulista, o sociólogo elenca três ocasiões que se constituíram em marcos para uma mudança neste sentimento. São elas: os momentos iniciais da imigração e a construção da "italianidade" fora da Itália, isto é, forjada na sociedade de acolhimento; a emergência do fascismo na Itália e sua tentativa de revigorar um sentimento nacional; e o Estado Novo e a campanha de nacionalização encetada por Vargas. Os meandros desses processos e os argumentos do autor serão elencados a seguir.

O capítulo "Uma italianidade construída em São Paulo" aponta que inicialmente, ao migrarem, estes sujeitos não possuíam uma "italianidade". Para corroborar esta afirmação o autor cita que Hobsbawm estimou que apenas 2,5\% falavam italiano na época em que a Itália foi unificada (p.36). Logo, a designação "italiano" foi cunhada em solo brasileiro pela própria sociedade 
receptora que, assim, denominava a todos os advindos deste mesmo espaço geográfico. Apesar de haver sido criada de maneira exógena, o autor acredita que esta circunstância promoveu consequências na formação de uma identidade comum dentro desta comunidade. A relação com outros, cujas fronteiras identitárias nacionais e raciais já estavam bem demarcadas, a exemplo dos negros, propiciou a criação de um reconhecimento de si por contraste. O grupo se afirmou enquanto branco e vinculado a uma valorização da ética do trabalho, de caráter preponderantemente individualista (p. 41). Apesar de trazer este contexto como o momento inicial de sua identificação enquanto grupo, Truzzi destaca que houve desafios para sua consolidação tanto em virtude dos regionalismos, que se faziam presentes na trajetória destes imigrantes, quanto em função de sua progressiva diferenciação social ao gerar reconhecimentos de classe que superavam a identificação étnica.

Nos capítulos "No meio rural" e "No meio urbano" o autor pontua episódios que foram relevantes na trajetória destes sujeitos e que impactaram na formação de um sentimento de pertencimento a uma mesma comunidade. Entre eles, a proibição em 1902 pelo governo italiano das passagens subsidiadas em função das precárias condições de trabalho nas fazendas de café. Esta promoveu a queda dos fluxos migratórios de italianos que foram substituídos por espanhóis e portugueses (p. 55-56), fato que enfraqueceu as possibilidades da formação da "italianidade".

Truzzi afirma que, para tentar articular estes indivíduos, a ação da imprensa, das escolas étnicas e das sociedades de auxílio mútuo desempenharam um papel significativo ao realizarem esforços para acomodar, em uma mesma instituição, indivíduos com credos e ideologias distintas. Contudo, a arregimentação e o entendimento entre estratos de uma colônia com diferenças de origem muito acentuadas foram árduos (p. 87) e pareceram se prestar mais aos interesses de uma camada bastante específica desta colônia. O autor tangencia o argumento de que uma "italianidade" ocorreu em função dos esforços de uma elite étnica que, ao integrar essas associações, visava se legitimar enquanto representante de uma numerosa coletividade e assim adquirir um prestígio que lhe outorgasse espaço nas oligarquias locais.

A efetivação da "italianidade" parece adquirir expressão a partir dos anos de 1920 com a emergência do fascismo na Itália. Ao propor uma vinculação direta entre regime e nação, o governo italiano entendia a comunidade dos emigrados como um importante representante e propagandista de seus interesses políticos e econômicos. Todavia, o autor destaca que a queda dos fluxos migratórios debilitava a adesão ao fascismo e que os filhos de imigrantes já se consideravam brasileiros e estavam mais propensos ao 
integralismo. Logo, o fascismo obteve impacto apenas entre os imigrantes que ascenderam socialmente e aspiravam se desvincular de sua aldeia de origem, e entre os comerciantes que viajavam para a Itália com frequência (p. 106). Para as classes subalternas essas questões permaneceram difusas e a condição de classe se fez mais presente que a étnica.

Por fim, o golpe final dado na tentativa da formação da "italianidade" foi perpetrado pelo Estado Novo que, com uma forte política nacionalista, reprimiu as escolas, imprensa e associações étnicas, ato que segundo o sociólogo fez com que o capital étnico migrasse para o social e político. Em fins dos anos de 1930 e especialmente no pós-Segunda Guerra, a "italianidade" não servia mais como legitimidade na comunidade já que a distância do processo migratório esvaziava o sentido de invocar essa noção (p. 120).

Ao fim do livro restam algumas indagações: afirmar a italianidade como uma comunidade imaginada, limitada e soberana aos moldes de Anderson não pressuporia especificidades em comum destes indivíduos? Atribuí-la a uma diferenciação com relação aos negros e ao fato de serem estrangeiros dentro de uma comunidade com costumes diferentes pode ser proposto a todas as comunidades de imigrantes. Indicar que a construção deste sentimento esbarrou em diferenças de formação social e histórica das diversas regiões da Itália implicaria que, para estes indivíduos, a noção de comunidade limitada nunca se fez presente.

Afirmar o protagonismo do imigrante no comércio e na indústria tanto como empresário quanto como empregado (p. 68), sem destacar todas as tensões que envolviam sua inserção na sociedade, oblitera um aspecto que foi relevante na formação destes indivíduos. Os imigrantes se tornaram a maior parte da população e exerceram inúmeras funções no campo e na cidade, o que gerou insegurança sobre como lidar com esse enorme contingente. No período abordado pelo autor, eram correntes os embates tensos entre a "assimilação" ou a "aculturação" destes indivíduos. ${ }^{4}$ Longe de embates que tensionavam constituírem uma população naturalizada no cotidiano, as

\footnotetext{
4 GORELIK, Ádrian. A aldeia na cidade. Ecos urbanos de um debate antropológico. In: LANNA, Ana Lucia Duarte; LIRA, José Tavares Correia de; PEIXOTO, Fernanda Arêas; SAMPAIO, Maria Ruth Amaral. São Paulo, os estrangeiros e a construção das cidades. São Paulo: Alameda Editorial, 2011; SEYFERTH, Giralda. Cartas e narrativas biográficas no estudo da imigração. In: DEMARTINI, Zeila de Brito Fabri \& TRUZZI, Oswaldo Mário Serra. Estudos migratórios: perspectivas metodológicas. São Paulo: EdUFSCar, 2005; PARK, Robert Ezra. A cidade: sugestões para a investigação do comportamento humano no meio urbano. In: VELHO, Otávio Guilherme (org.). O fenômeno urbano. $2^{\mathrm{a}}$ edição. Rio de Janeiro: Zahar Editores, 1973.
} 
crônicas e jornais demonstram que sua presença era percebida e incômoda. Foram criados estereótipos para as diferentes colônias que aqui aportaram, denotando uma insatisfação com a sua presença e demarcando-as como "o outro" na cidade. A respeito dos italianos houve a criação da imagem do "carcamano", termo pejorativo para designar os comerciantes.

A imagem de São Paulo como um local de convivência harmoniosa foi forjada ao longo dos anos, a partir de um discurso que tentava imprimir marcas cosmopolitas à cidade e ao estado. Os imigrantes que enriqueceram e os operários que participaram de movimentos políticos não foram vistos com bons olhos pelas famílias tradicionais. O suposto cosmopolitismo possuiu outras faces, nas quais o incentivo à imigração se inseriu em virtude do fim da outrora lucrativa escravidão e da política de embranquecimento atrelada à ideia de modernidade. Em decorrência desse projeto nem todos os imigrantes eram bem-vindos e, como propõe Sevcenko, a capital estava mais para um "Cativeiro da Babilônia" que para uma "Babel invertida", como sugeriu um cronista da época. ${ }^{5}$

Quanto ao fato de os imigrantes que adentraram na política não manejarem o capital étnico ao se colocarem como estrangeiros, pode-se indagar se isto não decorre da tentativa de ocupar espaços junto às oligarquias locais, tornando invisíveis suas origens para não parecerem uma ameaça aos nacionais. Para a historiadora Raquel Glezer a gênese da interpretação do passado colonial como um período glorioso foi cunhada neste momento em função da elite intelectual entender os imigrantes como uma ameaça constante que, uma vez trazidos para trabalhar na lavoura, impactaram a transformação do território. ${ }^{6}$ Logo, a análise de Truzzi não pontua alguns momentos relevantes na política e na legislação da cidade, necessários para pensar a inserção e as possíveis identidades manejadas pelos imigrantes ao atuarem nestes espaços.

Em termos metodológicos, em seus artigos mais recentes, tal como "Redes em processos migratórios",7 o sociólogo defende enfoques que caminhem no sentido de recuperar o papel do agente e de sua rede, fator decisivo na escolha dos locais de destino. Na abordagem proposta por Truzzi,

\footnotetext{
5 SEVCENKO, Nicolau. Orfeu extático na metrópole: São Paulo, sociedade e cultura nos frementes anos 20. São Paulo: Companhia das Letras, 1992, p. 37.

6 GLEZER, Raquel. Chão de terra e outros ensaios sobre São Paulo. São Paulo: Ed. Alameda, 2007, p. 179.

7 TRUZZI, Oswaldo Mario Serra. Redes em processos migratórios. Tempo Social (USP. Impresso), vol. 20, p. 199-218, 2008. Disponível em: http://www.revistas.usp.br/ts/article/view/12567. Acesso em: 6 jun. 2018. doi: http://dx.doi.org/10.1590/S0103-20702008000100010.
} 
visa-se dar ao imigrante um papel de agente racional, privilegiando o viés da micro-história na expectativa de encontrar a ação social e informações que se perderam nas escalas macroscópicas. Neste livro, apesar de realizar breves menções a imigrantes que atuaram nas cidades analisadas, não são consideradas suas trajetórias, usadas apenas para ilustrar algumas de suas proposições. Verifica-se tal procedimento ao versar sobre os imigrantes que, de forma precoce, adquiriram uma inserção privilegiada na sociedade de destino (p. 77). São citados alguns nomes e breves informações que não demonstram os meandros dessas ascensões sociais, gerando a heroicização desses self-made-men, uma vez que não há a significação e a problematização de suas trajetórias. Metodologia similar ocorre em relação à abordagem da iconografia que é utilizada ao longo do livro para corroborar suas afirmações, sem merecer maiores explanações.

A pertinência de Italianidade no interior paulista: percursos e descaminhos de uma identidade étnica (1880-1950) está em historicizar o termo "italianidade" mostrando seus desafios e particularidades em diferentes temporalidades. Contudo, o leitor ao fim do livro, percebe que ocorreram múltiplas criações de identidades étnicas, frutos de uma ação ativa destes indivíduos. Porém, não fica convencido da equivalência entre identidade étnica e "italianidade". A última parece nunca ter se efetivado para além de um projeto criado fora do grupo pela sociedade receptora e que, posteriormente, foi reapropriado por setores desta colônia que desejavam erigir seu poder simbólico.

\section{Referências bibliográficas}

BASSANEZI, Maria Silvia Casagrande Beozzo; SCOTT, Ana Silvia Volpi; BACELLAR, Carlos de Almeida Prado; TRUZZI, Oswaldo Mario Serra. Roteiro de fontes sobre a imigração em São Paulo 1850-1950. São Paulo: Unesp, 2008.

BASSANEZI, Maria Silvia Casagrande Beozzo; SCOTT, Ana Silvia Volpi; BACELLAR, Carlos de Almeida Prado; TRUZZI, Oswaldo Mario Serra; GOUVÊA, Marina Machado de Magalhães. Repertório de legislação brasileira e paulista referente à imigração. São Paulo: Editora Unesp, 2008.

BASSANEZI, Maria Silvia Casagrande Beozzo; SCOTT, Ana Silvia Volpi; BACELLAR, Carlos de Almeida Prado; TRUZZI, Oswaldo Mario Serra. Atlas da imigração internacional em São Paulo, 1850-1950. 1ª edição. São Paulo: Editora da Unesp, 2008.

GLEZER, Raquel. Chão de terra e outros ensaios sobre São Paulo. São Paulo: Ed. Alameda, 2007.

GORELIK, Ádrian. A aldeia na cidade. Ecos urbanos de um debate antropológico. In: LANNA, Ana Lucia Duarte; LIRA, José Tavares Correia de Lira; PEIXOTO, Fernanda Arêas; SAMPAIO, Maria Ruth Amaral. São Paulo, os estrangeiros e a construção das cidades. São Paulo: Alameda Editorial, 2011. 
KLEIN, Herbert. Migrações internacionais na história da América. In: FAUSTO, Boris. Fazer a América. São Paulo: Editora da Universidade de São Paulo, 2000.

OLIVEIRA, Lúcia Lippi. O Brasil dos imigrantes. Rio de Janeiro: Jorge Zahar Ed., 2002.

PARK, Robert Ezra. A cidade: sugestões para a investigação do comportamento humano no meio urbano. In: VELHO, Otávio Guilherme (org.). O fenômeno urbano. $2^{\text {a }}$ edição. Rio de Janeiro: Zahar Editores, 1973.

SEVCENKO, Nicolau. Orfeu extático na metrópole: São Paulo, sociedade e cultura nos frementes anos 20. São Paulo: Companhia das Letras, 1992.

SEYFERTH, Giralda. Cartas e narrativas biográficas no estudo da imigração. In: DEMARTINI, Zeila de Brito Fabri \& TRUZZI, Oswaldo Mário Serra. Estudos migratórios: perspectivas metodológicas. São Paulo: EdUFSCar, 2005.

TRUZZI, Oswaldo Mario Serra. Redes em processos migratórios. Tempo Social (USP. Impresso), vol. 20, p. 199-218, 2008. Patrícios - sírios e libaneses em São Paulo. São Paulo: Editora Unesp, 2008. Sírios e libaneses: narrativa de história e cultura. São Paulo: CEN, 2005. 